\title{
SOFTWARE UNTUK PENENTUAN LOKASI GANGGUAN JARINGAN DISTRIBUSI DENGAN METODE TAKAGI
}

\author{
Made Apri Sugiana1, Fachrudin Hunaini'2, Mohammad Muksim³ \\ 123 Teknik Elektro Universitas Widyagama Malang \\ Email : apri.sugiana@gmail.com
}

\begin{abstract}
Abstrak
Pada operasi sistem tenaga listrik dapat terjadi gangguan internal yaitu berasal dari sistem dan gangguan eksternal yaitu sambaran petir saat badai, hewan, atau pohon tumbang yang mengakibatkan terganggunya penyaluran tenaga listrik ke konsumen. Pada sistem kelistrikan pendeteksian lokasi gangguan secara cepat akan membantu melindungi peralatan, menjaga sistem tetap stabil dan meminimalkan kerusakan jaringan serta kerugian ekonomis. Metode simple reactance atau Metode berbasis impedansi menggunakan nilai dari fasor tegangan dan arus dari transduser seperti rele numerik dan perekam gangguan. Dengan teknik ini, fasor tegangan dan arus dapat diperoleh dari satu atau dua sumber di saluran distribusi. SedangkanMetode Takagi membutuhkan data sebelum gangguan untuk perhitungannya.Kunci keberhasilan dari metode Takagi ini adalah bahwa sudut $I_{s}$ sama dengan sudut If. Untuk sistem yang homogen yang ideal, sudut-sudut ini indentik. Maka dari itu dalam pembuatan skripsi ini memilih menggunakan Metode Takagi. Setelah melakukan analisis, maka dapat disimpulkan dengan menggunakan Metode Takagi mendapatkan nilai error rata-rata 0,003\% dibandingkan dengan menggunakan Metode Impedansi yang mendapatkan nilai error rata-rata 0,0142\%.
\end{abstract}

Kata kunci: Lokasi Gangguan, Metode Impedansi, Metode Takagi, Matlab GUI

\begin{abstract}
In the operation of the electric power system, internal disturbances can occur, namely from the system and external disturbances, namely lightning strikes during storms, animals, or fallen trees which result in disruption of electricity distribution to consumers. In electrical systems the detection of fault locations quickly will help protect equipment, keep the system stable and minimize network damage and economic losses. Simple reactance method or impedance based method uses the values of voltage and current phasors of the transducer such as numerical relay and interference recorder. With this technique, voltage and current phases can be obtained from one or two sources in the distribution channel. Whereas the Takagi Method requires data before interference for its calculations. The key to success of the Takagi method is that the angle Is equal to the If angle. For ideal homogeneous systems, these angles are identical. Therefore in making this thesis choose to use the Takagi Method. After conducting the analysis, it can be concluded that using the Takagi Method gets an average error value of $0.003 \%$ compared to using the Impedance Method which gets an average error value of $0.0142 \%$.
\end{abstract}

Keywords: Location of Interference, Impedance Method, Takagi Method, Matlab GUI

JASEE Journal of Application and Science on Electrical Engineering 


\section{PENDAHULUAN}

Gangguan internal dan eksternal dapat terjadi pada operasi sistem tenaga listrik berupa penggunaan beban yang melebihi kapasitas, kerusakan sistem maupun beban non-linear, sedangkan gangguan eksternal yaitu sambaran petir saat badai, hewan, atau pohon tumbang yang mengakibatkan terganggunya penyaluran tenaga listrik ke konsumen. Gangguan adalah penghalang dari suatu system yang sedang beroperasi atau suatu keadaan dari sistem penyaluran tenaga listrik yang menyimpang dari kondisi normal. Suatu gangguan di dalam peralatan listrik didefinisikan sebagai terjadinya suatu kerusakan di dalam jaringan listrik yang menyebabkan aliran arus listrik keluar dari saluran yang seharusnya[1]. Keadaan tersebut jika dibiarkan secara terus-menerus akan menyebabkan terjadinya penurunan keandalan sistem tenaga listrik dan kualitas energi listrik yang disalurkan serta menyebabkan kerusakan alat-alat yang bersangkutan.Permasalahan yang sering terjadi pada saluran distribusi adalah gangguan hubung singkat [2].

Pada PLN Rayon Grati juga sering mengalami gangguan jaringan tegangan menengah yaitu gangguan hubung singkat 1 fasa-tanah maupun gangguan hubung singkat fasa-fasa, berdasarkan data Jurnal Penyulang PLN Rayon Grati pada tahun 2018 Semester I terjadi 7 kali gangguan hubung singkat 1 fasa-tanah dan 8 kali gangguan hubung singkat fasa-fasa[3]. Seringkali lokasi gangguan tidak dapat segera diketahui letak lokasinya, sehingga memperlambat proses penanganan gangguan sehingga diperlukan suatu metode dalam perhitungan hubung singkat dan lokasi gangguan [4].

Metode yang sering digunakan dalam menganalisa titik lokasi gangguan ialah dengan menggunakan metode simple reactance, metode takagi, metode sequence dan perambatan gelombang sinyal arus balik. Berdasarkan penelitian yang telah dilakukan, metode takagi memiliki nilai rata-rata error 2,5\% untuk menentukan titik lokasi gangguan pada sistem jaringan listrik [2]. Berdasarkan penelitian yang telah dilakukan oleh Thoriq Aziz Al Qoyyimi, Ontoseno Penangsang, $\mathrm{Ni}$ Ketut Aryani (2017), tentang metode pendeteksian lokasi gangguan hubung singkat jaringan distribusi melalui metode impedansi berbasis Geographic Information System[4], maka dari itu dirancang suatu software dalam menentukan lokasi gangguan jaringan distribusi menggunakan metode Takagi, dimana penelitian ini diharapkan dapat mempermudah dalam penentuan lokasi gangguan dan mempercepat penormalan sistem tenaga listrik dengan nilai error yang minim.

\section{STUDI PUSTAKA}

\subsection{Sistem Operasi Jaringan Distribusi}

Sistem operasi jaringan distribusi merupakan bagian dari sistem tenaga listrik secara keseluruhan, sistem distribusi ini berguna untuk menyalurkan tenaga listrik dari sumber daya besar (Bulk Power Source) sampai kekonsumen. Pada umumnya sistem distribusi tenaga listrik di Indonesia terdiri atas beberapa bagian, sebagai berikut :

1. Gardu Induk (GI)

2. Jaringan Tegangan Menengah (TM) / Distibusi Primer

3. Gardu Distribusi (GD)

4. Jaringan Tegangan Rendah (TR) / Distribusi Sekunder

Gardu induk akan menerima daya dari jaringan transmisi kemudian menyalurkannya melalui jaringan distribusi primer menuju gardu distribusi. 
Sistem jaringan distribusi terdiri dari dua bagian yaitu jaringan distribusi primer dan jaringan distribusi sekunder. Jaringan distribusi primer umumnya bertegangan menengah $20 \mathrm{kV}$. Tegangan tersebut kemudian diturunkan oleh transformator distribusi pada gardu distribusi menjadi tegangan rendah (220/380 volt) untuk selanjutnya disalurkan kepada konsumen melalui jaringan distribusi sekunder.
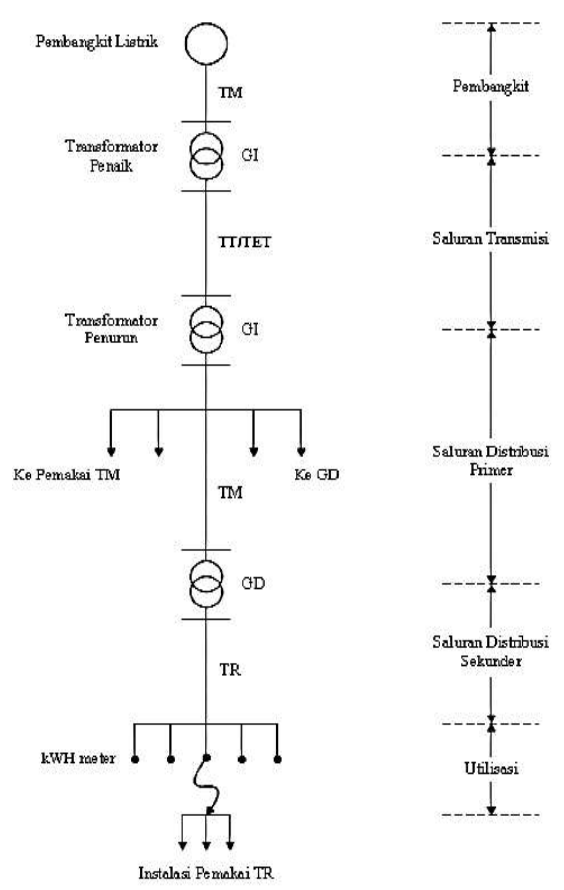

Gambar 1. Sistem Tenaga Listrik

\subsection{Sistem Distribusi Radial}

Bentuk jaringan ini merupakan bentuk yang paling sederhana, banyak digunakan dan murah. Dinamakan radial karena saluran ini ditarik secara radial dari suatu titik yang merupakan sumberdari jaringan itu dan dicabang cabangkan ke titik - titik beban yang dilayani.

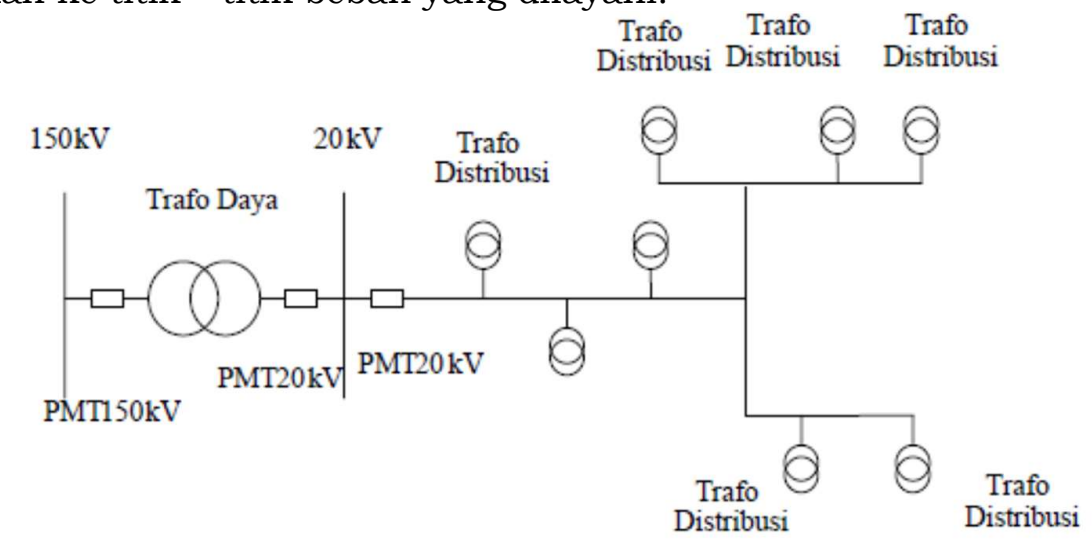

Gambar 2. Sistem Distribusi Radial

Catu daya berasal dari satu titik sumber dan karena adanya pencabangan - pencabangan tersebut, maka arus beban yang mengalir disepanjang saluran menjadi tidak sama sehingga luas penampang konduktor pada jaringan bentuk JASEE Journal of Application and Science on Electrical Engineering 42 https://doi.org/10.31328/iasee.v1i01.5 
radial ini ukurannya tidak sama sehingga luas penampamg konduktor pada jaringan bentuk radial ini ukurannya tidak sama karena arus yang paling besar mengalir pada jaringan yang paling dekat dengan gardu induk. Sehingga saluran yang paling dekat dengan gardu induk ini ukuran penampangnya relatif besar dan saluran cabang - cabangnya makin ke ujung dengan arus beban yang lebih kecil mempunyai ukuran konduktornya lebih kecil pula. Spesifikasi dari jaringan bentuk radial ini adalah :

1. Bentuknya sederhana.

2. Biaya inverstasinya murah

3. Kualitas pelayanan dayanya relatif jelek, karena rugi tegangan dan rugi daya yang terjadi pada saluran relatif besar.

4. Kontinuitas pelayanan daya kurang terjamin sebab antara titik sumber dan titik beban hanya ada satu alternatif saluran sehingga bila saluran tersebut mengalami pemadaman total, yaitu daerah saluran sesudah atau dibelakang titik gangguan selama gangguan belum teratasi.

Untuk melokalisisr gangguan pada bentuk radial ini biasanya dilengkapi dengan peralatan pengaman, fungsinya untuk membatasi daerah yang mengalami pemadaman total, yaitu daerah saluran sesudah atau dibelakang titik gangguan selama gangguan belum teratasi.

\subsection{Gangguan pada Jaringan Distribusi Tenaga Listrik}

Dalam operasi sistem tenaga listrik sering terjadi gangguan yang dapat mengakibatkan terganggunya penyaluran tenaga listrik ke konsumen. Gangguan adalah suatu keadaan dari sistem penyaluran tenaga listrik yang menyimpang dari keadaan normal. Berdasarkan ANSI/IEEE Std 100-1992 gangguan didefinisikan sebagai suatu kondisi fisis yang disebabkan kegagalan suatu perangkat, komponen atau suatu elemen untuk bekerja sesuai dengan fungsinya. Hubung singkat ialah suatu hubungan abnormal (termasuk busur api) pada impedansi yang relatif rendah terjadi secara kebetulan atau disengaja antara dua titik yang mempunyai potensial yang berbeda. Pada dasarnya gangguan yang sering terjadi pada sistem distribusi saluran $20 \mathrm{kV}$ menjadi dua macam yaitu gangguan dari dalam sistem dan gangguan dari luar sistem.

Gangguan yang berasal dari dalam sistem dapat berupa kegagalan dari fungsi peralatan jaringan, kerusakan dari peralatan jaringan dan kerusakan dari peralatan pemutus beban. Gangguan yang berasal dari luar sistem dapat disebabkan oleh sentuhan pohon atau ranting pada penghantar, sambaran petir, manusia, binatang, cuaca dan lain-lain. Jenis gangguan yang terjadi pada jaringan distribusi dapat dibagi menjadi 2, yaitu

a. Dari lama gangguan :

1. Gangguan permanen (dapat disebabkan oleh kerusakan peralatan, gangguan baru akan hilang setelah kerusakan diperbaiki).

2. Gangguan temporer (gangguan yang tidak akan lama dan dapat normal atau hilang dengan sendirinya yang disusul dengan penutupan kembali peralatan hubungnya).

b. Dari jenis gangguan :

1. Gangguan satu fasa ke tanah

2. Gangguan dua fasa ke tanah

3. Gangguan fasa ke fasa

4. Gangguan tiga fasa ke tanah 


\subsection{Gangguan Hubung Singkat}

Gangguan hubung singkat adalah gangguan yang terjadi karena adanya kesalahan antara bagian-bagian yang bertegangan dapat penyebabkan terjadinya arus yang sangat besar, sehingga dapat merusak peralatan listrik yang ada di sekitar titik gangguan. Dari jenis gangguannya :

1. Gangguan Satu Fasa ke Tanah

2. Gangguan Fasa-Fasa

3. Gangguan Tiga Fasa

\subsection{Metode Takagi}

Metode Takagi membutuhkan data sebelum gangguan dan data setelah gangguan. Metode ini mengurangi efek dari aliran beban dan meminimalkan efek tahanan gangguan [8].

$$
V s=m \times Z 1 L \times I+R f \times I f
$$

Agar dapat menemukan persamaan pada fasa dengan If, maka dibutuhkan arus superposisi (Isup):

$$
\text { I sup }=I-\text { Ipre }
$$

Dimana :

I : arus gangguan

Ipre : arus sebelum gangguan

Teganggan drop dari bus $\mathrm{S}$ :

$$
V s=m \times Z 1 L \times I s+R f \times I f
$$

Gabungan dari kedua sisi persamaan dengan konjuget yang komplit dari Isup (Isup*) dan bagian imaginer ditetapkan. Kemudian, untuk $m$ ditentukan.

$$
\begin{aligned}
& \operatorname{Im}\left[\mathrm{Vs} \cdot \operatorname{Isup}{ }^{*}\right]=\mathrm{m} \cdot \operatorname{Im}\left(\mathrm{Z} 1 \mathrm{~L} \cdot \mathrm{Is} \cdot \operatorname{Isup}{ }^{*}\right)+\mathrm{Rf} \cdot \operatorname{Im}\left(\mathrm{If} \cdot \mathrm{Isup}^{*}\right) \\
& m=\frac{\operatorname{Im}(V s * I \text { superposisi })}{\operatorname{Im}(Z 1 L * I S * I \text { superposisi })}
\end{aligned}
$$

\section{Keterangan :}

$$
\begin{array}{ll}
\mathrm{m} & : \text { Lokasi Gangguan } \\
\mathrm{Im} & : \text { Arus Gangguan } \\
\mathrm{Vs} & : \text { Tegangan drop sumber } \\
\mathrm{Z} 1 \mathrm{~L} & : \text { Impedansi Jaringan Line } \\
\mathrm{Is} & : \text { Arus Sumber } \\
\mathrm{I} \text { sup } & : \text { Arus Superposisi }
\end{array}
$$

Pada metode Takagi data tegangan yang akan digunakan setelah gangguan tiga fasa, menggunakan rumus sebagai berikut:

dimana,

$$
\text { Vtakagi }=\frac{V 3 p}{\sqrt{3}}
$$

V3p : Nilai tegangan pada gangguan tiga fasa

\subsection{MATLAB GUI 2016}

GUIDE atau GUI builder merupakan sebuah graphical user interface (GUI) yang dibangun dengan obyek grafik seperti tombol (button), kotak teks, slider, menu dan lain-lain. Aplikasi yang menggunakan GUI umumnya lebih mudah dipelajari dan digunakan karena orang yang menjalankannya tidak perlu 
mengetahui perintah yang ada dan bagaimana kerjanya. Sampai saat ini, jika kita membicarakan pemrograman berorientasi visual, yang ada di benak kita adalah sederetan bahasa pemrograman, seperti visual basic, Delphi, visual $\mathrm{C}++$, visual Fox Pro, dan lainnya yang memang didesai secara khusus untuk itu. Matlab merintis ke arah pemrograman yang menggunakan GUI dimulai dari versi 5 , yang terus disempurnkan sampai sekarang (Matlab 9).

GUIDE Matlab mempunyai kelebihan tersendiri dibandingkan dengan bahasa pemrogram lainnya, diantaranya:

1. GUIDE Matlab banyak digunakan dan cocok untuk aplikasi-aplikasi berorientasi sains, sehingga banyak peneliti dan mahasiswa menggunakan GUIDE Matlab untuk menyelesaikan riset atau skripsinya.

2. GUIDE Matlab mempunyai fungsi built-in yang siap digunakan dan pemakai tidak perlu repot membuatnya sendiri.

3. Ukuran file, baik FIG-file maupun M-file, yang dihasilkan relatif kecil.

4. Kemampuan grafisnya cukup andal dan tidak kalah dibandingkan dengan bahasa pemrograman lainnya.

\section{METODE}

Metode penelitian yang dilakukan meliputi tahapan antara lain : pengambilan data sampel, pembuatan program software, pengujian dan validasi softwrae. Data sampel adalah data transformator berupa tipe, kapasitas daya, tegangan kerja, arus nominal, belitan delta, impedansi, vektor group dan pentanahan. Untuk membangun software, maka dilakukan perencanaan meliputi pembuatan alur kerja software, pembuatan database dan pengkodean dengan bahasa pemrograman Matlab.

Diagram alir dari software yang dikembangkan sebagaimana ditunjukkan oleh Gambar 3. Langkah awal dalam pemrograman yaitu dengan input atau load data penyulang yang telah dibuat terlebih dahulu pada program MATLAB, selanjutnya input load data parameter penyulang, dimana data parameter ini yaitu data-data transformator tenaga pada Gardu Induk sesuai data parameter pada tampilan awal aplikasi. Setelah Load data-data tersebut maka data tersebut di tampilkan pada tabel program. Proses load data-data selesai, selanjutnya memprogram pemilihan jenis gangguan yang terjadi dengan menu pilih jenis gangguan. Apabila jenis gangguan yang dipilih adalah gangguan DGR (1 fasa ke tanah) maka akan langsung diproses perhitungan, jika tidak akan memilih gangguan OCR (2 fasa) atau OCR Instant (gangguan 3 fasa). Setelah menentukan pilihan jenis gangguan, selanjutnya memasukkan nilai arus gangguan yang terjadi, apabila nilai valid maka diproses perhitungan untuk mendapatkan titik estimasi lokasi gangguan dalam kilometer $(\mathrm{km})$. 
| Vol. 1 | No. 1| Halaman 40 - 50

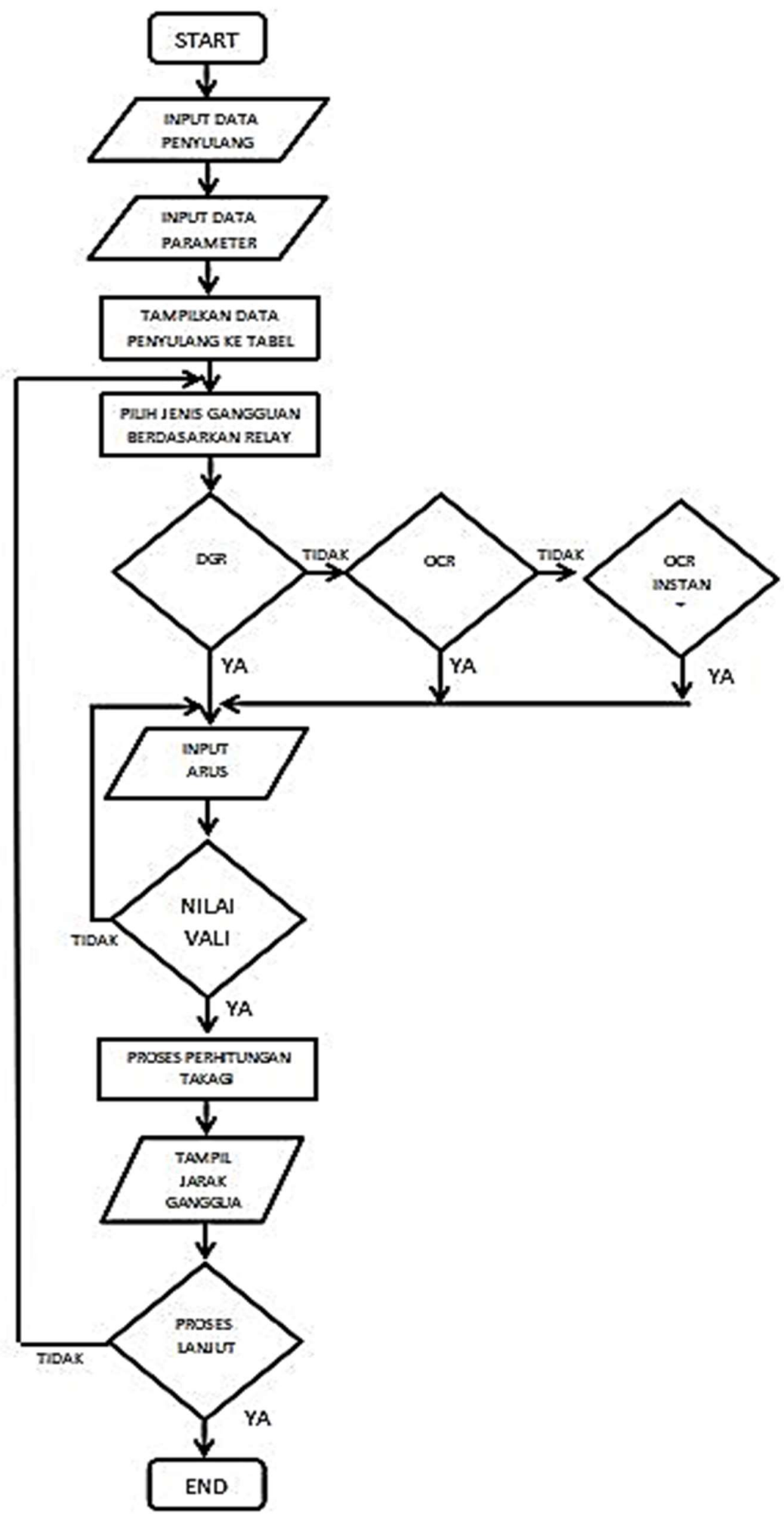

Gambar 3. Diagram alir perancangan software 


\section{HASIL DAN PEMBAHASAN}

\subsection{Gambaran Umum Penyulang Ngopak}

Penyulang Ngopak disuplai melalui trafo tenaga berkapasitas 60 MVA dengan data teknis trafo tenaga ditunjukkan pada tabel 4.1.

Tabel 1 Data Trafo I GI Gd Wetan

\begin{tabular}{|c|c|c|c|}
\hline No & Data Teknis & Uraian & Satuan \\
\hline 1 & Merek & UNINDO & - \\
\hline 2 & Type & A 9315144-02 & - \\
\hline 3 & No. Seri & A 9315144-02 & - \\
\hline 4 & Kapasitas/Daya & 60 & MVA \\
\hline 5 & Tegangan Kerja & $150 / 20$ & $\mathrm{kV}$ \\
\hline 6 & Arus Nominal & $230 / 1732$ & $\mathrm{~A}$ \\
\hline 7 & Isc pada Sisi 150 kV & 9164 & $\mathrm{~A}$ \\
\hline 8 & Impedansi & 13 & $\%$ \\
\hline 9 & Belitan Delta & Ada & - \\
\hline 10 & Vektor Group & Ynyn0(d1) & - \\
\hline 11 & Tahun Buatan & 1993 & - \\
\hline 12 & Pentanahan & 40 & $\Omega$ \\
\hline
\end{tabular}

Penyulang Ngopak memiliki panjang 30,491 kms dengan data teknis penghantar pada jaringan utama ditunjukkan pada table 4.2.

Tabel 2 Data Penghantar Penyulang Ngopak

\begin{tabular}{|l|c|}
\hline \multicolumn{1}{|c|}{ Penghantar $\left(\mathrm{mm}^{2}\right)$} & Panjang $(\mathrm{km})$ \\
\hline $\begin{array}{l}\text { NA2XSEFGBY 3 X } \\
240\end{array}$ & 0,137 \\
\hline AAAC 3 X 150 & 9,148 \\
\hline AAAC 3 X 150 & 14,889 \\
\hline AAACS 3 X 150 & 0,067 \\
\hline AAAC 3 X 70 & 5,249 \\
\hline AAAC 3 X 50 & 1,001 \\
\hline Total & 30,491 \\
\hline
\end{tabular}

Pada analisis komparasi dan pembahasan pengujian aplikasi ini, terlebih dahulu akan melakukan perhitungan jarak gangguan dan besar arus gangguan dengan menggunakan Metode berbasis Impedansi dan dilanjutkan dengan menganalisis hasil aplikasi menggunakan Metode Takagi serta mendapatkan nilai error.

\subsection{Perhitungan Lokasi Gangguan Menggunakan Metode Impedansi}

Perhitungan dengan Metode berbasis Impedansi ini dapat menentukan jarak gangguan dengan menggunakan besar nilai impedansi jaringan yang terjadi gangguan. Hasil perhitungan Metode Impedansi berupa jarak gangguan dan besar JASEE Journal of Application and Science on Electrical Engineering 
nilai arus gangguan yang akan dihitung berdasarkan studi kasus pada PT. PLN Rayon Grati di Penyulang Ngopak yang terjadi gangguan jaringan distribusi dengan parameter relay Over Current Relay (OCR) dan arus gangguan 1.083,220 Ampere. Maka perhitungan dengan menggunakan Metode Impedansi sebagai berikut :

$$
\begin{aligned}
& I_{h s 2 \text { fasa }}=\frac{E_{p h-p h}}{Z_{1 e q}+Z_{2 e q}} I_{h s 2 \text { fasa }}=\frac{E_{p h-p h}}{2 x Z_{1 e q}} \quad 1083=\frac{20000}{2 \times Z 1 e q} \\
& 2166 Z 1 e q=20000 \\
& Z 1 e q=\frac{20000}{2166} \\
& Z 1 e q=9,233 \mathrm{ohm} / \mathrm{km}
\end{aligned}
$$

Berdasarkan hasil Impedansi yang didapat, maka selanjutnya akan disesuaikan dengan jarak dan impedansi. Untuk hasil 9,233 ohm $/ \mathrm{km}$ mendapatkan jarak lokasi gangguan yaitu $19,9 \mathrm{~km}$.

Dengan menggunakan persamaan diatas maka untuk studi kasus selanjutnya dapat dihitung dan hasil sesuai tabel dibawah ini :

Tabel 3. Hasil Perhitungan Metode Impedansi

\begin{tabular}{|c|c|c|c|c|c|}
\hline No & Jenis Gangguan & $\begin{array}{c}\text { Arus } \\
\text { Gangguan } \\
(\mathrm{A})\end{array}$ & $\begin{array}{c}\text { Jarak } \\
\text { sebenarnya } \\
(\mathrm{km})\end{array}$ & $\begin{array}{c}\text { Jarak Metode } \\
\text { Impedansi }(\mathrm{km})\end{array}$ & $\begin{array}{c}\text { Error Metode } \\
\text { Impedansi (\%) }\end{array}$ \\
\hline 1 & DGR & 280 & 1,5 & 1,57 & 0,0466 \\
\hline 2 & DGR & 210 & 27,5 & 27,75 & 0,009 \\
\hline 3 & OCR & 1083 & 19,8 & 19,9 & 0,00505 \\
\hline 4 & OCR & 1362 & 15,6 & 15,7 & 0,0064 \\
\hline 5 & OCR INSTANT & 919 & 27,3 & 27,41 & 0,00402 \\
\hline
\end{tabular}

\subsection{Pengujian Software Penentuan Lokasi Gangguan Menggunakan Metode Takagi}

Dengan menggunakan software tersebut maka untuk hasil estimasi jarak lokasi ganguan pada studi kasus Penyulang Ngopak PLN Rayon Grati dapat dilihat sesuai tabel dibawah ini :

Tabel 4. Hasil Pengujian Sotware Menggunakan Metode Takagi

\begin{tabular}{|c|c|c|c|c|c|}
\hline No & Jenis Gangguan & $\begin{array}{c}\text { Arus } \\
\text { Gangguan } \\
(\mathrm{A})\end{array}$ & $\begin{array}{c}\text { Jarak } \\
\text { sebenarnya } \\
(\mathrm{km})\end{array}$ & $\begin{array}{c}\text { Jarak Metode } \\
\text { Takagi }(\mathrm{km})\end{array}$ & $\begin{array}{c}\text { Error Metode } \\
\text { Takagi (\%) }\end{array}$ \\
\hline 1 & DGR & 280 & 1,5 & 1,4856 & 0,0096 \\
\hline 2 & DGR & 210 & 27,5 & 27,5222 & 0,000807 \\
\hline 3 & OCR & 1083 & 19,8 & 19,888 & 0,0044 \\
\hline 4 & OCR & 1362 & 15,6 & 15,6468 & 0,003 \\
\hline 5 & OCR INSTANT & 919 & 27,3 & 27,3101 & 0,00036 \\
\hline
\end{tabular}




\subsection{Analisis Komparasi Software Penentuan Lokasi Gangguan Menggunakan Metode Takagi}

Berdasarkan hasil pengujian, maka analisis komparasi yang dilakukan dengan membandingkan hasil dari perhitungan dengan Metode Impedansi dengan hasil pengujian aplikasi penentuan lokasi gangguan menggunakan Metode Takagi, sesuai dengan hasil tabel dibawah ini :

Tabel 5. Analisis Komparasi Hasil

\begin{tabular}{|c|c|c|c|c|c|c|c|}
\hline No & $\begin{array}{c}\text { Jenis } \\
\text { Gangquan }\end{array}$ & $\begin{array}{c}\text { Arus } \\
\text { Gangguan } \\
(\mathrm{A})\end{array}$ & $\begin{array}{c}\text { Jarak } \\
\text { sebenamya } \\
(\mathrm{km})\end{array}$ & $\begin{array}{c}\text { Jarak } \\
\text { Metode } \\
\text { Impedansi } \\
(\mathrm{km})\end{array}$ & $\begin{array}{c}\text { Jarak Metode } \\
\text { Takagi }(\mathrm{km})\end{array}$ & $\begin{array}{c}\text { Error Metode } \\
\text { Impedansi } \\
(\%)\end{array}$ & $\begin{array}{c}\text { Error Metode } \\
\text { Takagi (\%) }\end{array}$ \\
\hline 1 & DGR & 280 & 1,5 & 1,57 & 1,4856 & 0,0466 & 0,0096 \\
\hline 2 & DGR & 210 & 27,5 & 27,75 & 27,5222 & 0,009 & 0,000807 \\
\hline 3 & OCR & 1083 & 19,8 & 19,9 & 19,888 & 0,00505 & 0,0044 \\
\hline 4 & OCR & 1362 & 15,6 & 15,7 & 15,6468 & 0,0064 & 0,003 \\
\hline 5 & OCR & 919 & 27,3 & 27,41 & 27,3101 & 0,00402 & 0,00036 \\
\hline & \multicolumn{7}{|c|}{ Rata-Rata Error } \\
\hline
\end{tabular}

Berdasarkan pada tabel 5 diatas, dapat dilihat bahwa hasil pengujian aplikasi penentuan lokasi gangguan jaringan distribusi menggunakan Metode Takagi dari studi kasus gangguan jaringan distribusi pada Penyulang Ngopak mendapatkan nilai rata-rata error yaitu 0,003 \%, yang lebih kecil dibandingkan Metode Impedansi dengan nilai error rata-rata yaitu 0,0142 \%.

\section{KESIMPULAN}

Berdasarkan hasil pengujian dan analisa software penentuan lokasi gangguan jaringan distribusi, maka dapat disimpulkan bahwaSoftware penentuan lokasi gangguan jaringan distribusi yang dirancang menggunakan MATLAB GUI dengan memproses data-data penyulang, data impedansi dan arus gangguan berdasarkan parameter relay menggunakan Metode Takagi sehingga mendapatkan estimasi jarak lokasi gangguan jaringan distribusi. Berdasarkan hasil analisis komparasi antara Metode Impedansi dan Aplikasi Penentuan Lokasi Gangguan Jaringan Distribui menggunakan Metode Takagi memiliki nilai rata-rata error yaitu 0,003\%, dibandingkan dengan Metode Impedansi yaitu 0,0142 \%.

\section{DAFTAR RUJUKAN}

[1] S. Wahyudi, Buku Saku Proteksi Sistem Distribusi Tenaga Listrik, 2012 ed., vol. 1. 2012.Garamond.

[2] Y. S. Agus dan E. Ervianto, "Menentukan Lokasi Gangguan Dengan Metode Simple Reactance dan Takagi Pada Saluran Distribusi Bangko PT. Chevron Pacific Indonesia Menggunakan Software ETAP 12.6.0," Jurnal Online Mahasiswa (JOM) Fakultas Teknik Universitas Riau, vol. 3, hlm. 7, 2016.

[3] Anonim, "Laporan Gangguan Penyulang PLN Rayon Grati.", Laporan PLN Rayon Grati Bulan Mei 2018, 31-Mei-2018.

[4] T. A. A. Qoyyimi, O. Penangsang, N. K. Aryani, dan J. A. R. Hakim, "Penentuan Lokasi Gangguan Hubung Singkat pada Jaringan Distribusi 20 kV Penyulang 
Tegalsari Surabaya dengan Metode Impedansi Berbasis GIS (Geographic Information System)," Jurnal Teknik ITS, vol. 6, no. 1, hlm. 6, 2017.

[5] Hendriyadi, "Perhitungan Arus Gangguan Hubung Singkat pada Jaringan Distribusi di Kota Pontianak," Jurnal Mahasiswa Jurusan Teknik Elektro, Fakultas Teknik, Universitas Tanjungpura Pontianak, 2010.

[6] A. Hermawan, Transmisi dan Distribusi Tenaga Listrik, Jurnal Cyclotron, Program Studi Teknik Elektro, Universitas Muhammadiyah Surabaya, 2003.

[7] D. Suswanto, "Sistem Distribusi Tenaga Listrik," Univ. Negeri Padang, Jul 2009.

[8] T. Takagi, "Development of a New Type Fault Locator Using The One-Terminal Voltage and Current Data," Journals IEEE Transactions on Power Apparatus and Systems, vol. PAS-101 No.8, Agu 1982. 